\title{
Iniciativas informacionais do Instituto Brasileiro de Informação em Ciência e Tecnologia (lbict) em tempos da pandemia
}

\author{
Information initiatives of the Brazilian Institute of Information on \\ Science and Technology (Ibict) in pandemic times
}

\author{
Bianca Amaro ${ }^{\text {(D) }}$ \\ Fhillipe de Freitas Campos ${ }^{\mathrm{a}, \text { * (D) }}$ \\ Luciana dos Santos Nahuza (i) \\ Raphael Faria Vilas Boas ${ }^{a}$ \\ Juliana Araujo Gomes de Sousa ${ }^{a}$ (D) \\ Vanderlino Coelho Barreto Neto ${ }^{a, b}$ (D) \\ Leonard Richard Rodrigues Rufino Campêlo ${ }^{\mathrm{a}}$ \\ Lucas Nóbrega Paganinea (D) \\ Danielly dos Santos Ribeiroa \\ Flávio Jesus dos Santosa (it)
}

Washington Luís Ribeiro de Carvalho Segundoa (D)

\begin{abstract}
RESUMO: O Acesso Aberto e a Ciência Aberta são movimentos mundiais e com potenciais benefícios ao processo científico em todas as áreas do conhecimento. Ciente destes benefícios, e frente à pandemia causada pelo novo coronavírus, o Instituto Brasileiro de Informação em Ciência e Tecnologia (Ibict) realizou uma série de iniciativas com o objetivo de facilitar a encontrabilidade de fontes de informações científicas confiáveis sobre a temática. Entre essas iniciativas, três são objetos de estudo deste relato: o Diretório de fontes de informação científica de livre acesso sobre o Coronavírus, o Repositório de preprints Emerging Research Information (EmeRI) e a Rede de Especialistas e Pesquisas. As três iniciativas foram desenvolvidas por uma equipe multidisciplinar das áreas de Ciência da Informação e de Tecnologia da Informação durante o regime de teletrabalho e a partir de uma série de ações coordenadas. Os principais resultados mostram que as ferramentas desenvolvidas estão sendo acessadas e utilizadas, contudo, as informações presentes no Relato apontam para a importância da execução de melhorias na atualização e manutenção dos sistemas, refletindo a necessidade de modernização das estratégias adotadas pela equipe desenvolvedora, principalmente no período pós-pandemia.
\end{abstract}

Palavras-chave: Ciência Aberta; Fontes de Informação; Comunicação Científica; Covid-19; Coronavírus.

ABSTRACT: Open Access and Open Science are worldwide movements with potential benefits to the scientific process in all areas of knowledge. Aware of these benefits, and facing the pandemic caused by the new coronavirus, the Brazilian Institute of Information in Science and Technology (Ibict) carried out a series of initiatives with the objective of facilitating the finding of reliable scientific information sources on the subject. Among these initiatives, three are objects of study in this report: the Directory of scientific information sources of free access about the Coronavirus, the Preprint Repository Emerging Research

a Coordenação de Tratamento, Análise e Disseminação da Informação Científica, Instituto Brasileiro de Informação em Ciência e Tecnologia, Brasília, DF, Brasil.

b Comissão Nacional de Energia Nuclear, Rio de Janeiro, RJ, Brasil.

* Correnspondência para/Correspondence to: Fhillipe de Freitas Campos. E-mail: fhillipecampos@ibict.br. Endereço institucional: Setor de Autarquias Sul (SAUS) Quadra 5 - Lote 6, Bloco H, $4^{\circ}$ andar, Sala 402. Brasília - DF, 70070-912. Telefone: (55 61) 3217-6449

Recebido em/Received: 28/08/2020; Aprovado em/Approved: 23/10/2020.

Artigo publicado em acesso aberto sob licença CC BY 4.0 Internacional $@(i)$ 
Information (EmeRI) and the Network of Experts and Research. The three initiatives were developed by a multidisciplinary team in the areas of Information Science and Information Technology during the teleworking regime and based on a series of coordinated actions. The main results show that the tools developed are being accessed and used, however, the information in the Report points to the importance of making improvements in updating and maintaining systems, reflecting the need to modernize the strategies adopted by the development team, especially in the post-pandemic period.

Keywords: Open Science; Information Sources; Scientific Communication; Covid-19; Coronavírus.

\section{INTRODUÇÃO}

A pandemia da Covid-19 causou uma crise mundial que afetou praticamente todas as facetas da sociedade, fazendo com que novas formas de agir precisassem ser adotadas. Em relação ao fazer científico, ficou notória, a urgência que as áreas da saúde possuem em publicar e ter acesso aos resultados de pesquisas científicas sobre Covid-19, bem como a necessidade de transparência dos métodos utilizados para se chegar àquele resultado. O modelo tradicional de comunicação científica possui uma série de barreiras que estão distribuídas em diferentes etapas do processo de comunicação, gerando gargalos para o acesso, disseminação e democratização do conhecimento produzido.

Neste sentido, e a partir do Movimento de Acesso Aberto, ficou latente a necessidade de se ampliar as práticas do fazer científico por meio de um movimento ainda mais transparente, que, então, passou a denominar-se Ciência Aberta. Trata-se de um termo guarda-chuva que relaciona os princípios da abertura e colaboração nos diversos processos científicos. A Ciência Aberta possui características imprescindíveis ao momento, como, por exemplo, o incentivo ao compartilhamento de dados de pesquisa, como também dos resultados das pesquisas por meio de preprints.

Ciente dos benefícios que a Ciência Aberta pode trazer para as pesquisas científicas, e em especial neste momento de pandemia, o Instituto Brasileiro de Informação em Ciência e Tecnologia (Ibict), unidade de pesquisa vinculada ao Ministério da Ciência, Tecnologias e Inovações (MCTI), realizou uma série de ações com o objetivo de facilitar a visibilidade e encontrabilidade de informações científicas que dizem respeito ao assunto. Para isso, foram desenvolvidas três iniciativas: o Diretório de fontes de informação científica de livre acesso sobre o Coronavírus ${ }^{1}$, o Repositório de preprints Emerging Research Information (EmeRI) ${ }^{2}$ e a Rede de Especialistas e Pesquisas ${ }^{3}$.

A elaboração dos sistemas citados envolveu o trabalho de uma equipe multidisciplinar das áreas de Ciência da Informação e Tecnologia da Informação, onde atuaram nas atividades de criação, implementação e manutenção dos três sistemas.

\section{METODOLOGIA}

Este trabalho trata-se de um relato de experiência das ações informacionais desenvolvidas pelo Ibict em prol do combate à pandemia. O relato aborda os processos de planejamento, implementação e lançamento de três sistemas que visam prover e agregar informações científicas e tecnológicas, nacionais e internacionais, que dizem respeito ao novo coronavírus. Os sistemas foram desenvolvidos por pesquisadores do

\footnotetext{
${ }^{1}$ Disponível em: <http://diretoriodefontes.ibict.br/coronavirus/>

${ }^{2}$ Disponível em: <https://preprints.ibict.br/>

3 Disponível em: <http://especialistasepesquisas.ibict.br/wordpress/>
} 
Ibict, com o apoio de instituições parceiras e tiveram seu início a partir de março de 2020, momento em que o Brasil apresentou crescimento exponencial na curva de contágio do vírus.

A metodologia de trabalho se baseou na divisão de tarefas entre os membros da equipe, onde uma parte ficou responsável pela área informacional dos sistemas, que envolveu: busca de fontes, elaboração e descrição de metadados, definição de termos de busca, recuperação de especialistas, arquitetura da informação, etc; e a outra parte ficou responsável pelas questões tecnológicas, que envolveu a escolha e instalação das ferramentas a serem utilizadas, posterior implementação, migração para servidores de produção, bem como a resolução de outros percalços que, por ventura, surgiram durante o processo.

\section{DIRETÓRIO DE FONTES DE INFORMAÇÃO CIENTÍFICA DE LIVRE ACESSO SOBRE O CORONAVÍRUS}

Desde que o novo coronavírus, Covid-19, foi registrado na China, no final de 2019, o mundo percebeu a necessidade de se unir em prol de um bem comum, a pesquisa científica, de modo a desenvolver tratamentos, métodos, vacinas, etc., para combatêlo.

O Acesso Aberto e a Ciência Aberta se tornaram ainda mais necessários neste momento, e, diante disso, renomadas editoras científicas comerciais, que historicamente detém e cobram pelo acesso aos artigos publicados em suas revistas, disponibilizaram, por tempo determinado, coleções específicas com acesso livre aos artigos e outras pesquisas que tecem relação com o tema coronavírus - Covid-19. Além disso, observaram-se também alguns movimentos em direção à abertura dos dados de pesquisa, da publicação de preprints e de métodos de tratamento experimentais e em andamento, este último, por meio de bases de evidências científicas.

Neste contexto, o volume de informação disponível e acessível para todos na web, que já era amplo, sofreu uma espécie de explosão informacional, dado que a produção e divulgação de informações em diversos meios digitais acelerou-se de maneira abrupta. Apesar disso, a credibilidade e cientificidade desses conteúdos carece de certa curadoria. Assim sendo, o Ibict em parceria com a Organização das Nações Unidas para a Educação, a Ciência e a Cultura (Unesco), identificaram a necessidade de concentrar as informações científicas dispersas em diversos ambientes (sites de editoras comerciais, repositórios de preprints, revistas científicas, sites de organismos internacionais, institutos médicos, universidades, etc.) em uma única plataforma, levando à criação do Diretório de fontes.

Contando, atualmente, com 94 fontes de informações científicas, o Diretório foi lançado no dia 20 de maio de 2020 e está disponível para acesso desde então via internet. Destaca-se que o Diretório é um trabalho colaborativo de identificação de recursos informacionais e que seu conteúdo está em constante desenvolvimento e curadoria. Além disso, qualquer usuário pode indicar, via e-mail ${ }^{4}$, uma fonte que ainda não esteja listada no diretório, desde que atenda a premissa básica de possuir conteúdos científicos sobre o coronavírus e em acesso aberto. As indicações são analisadas pela equipe gestora do Diretório e, se aprovadas, passarão a incorporá-lo.

4E-mail de contato: diretoriodefontes@ibict.br 
Para a seleção das fontes de informação, a equipe responsável pela criação do Diretório discutiu sobre qual seria a melhor maneira de agrupá-las e a ferramenta tecnológica mais adequada, para, então, dar início à implementação. Esta fase foi uma das mais importantes do processo, pois possibilitou a melhor disposição das fontes selecionadas, guiando assim seu desenvolvimento.

\section{Aspectos informacionais do Diretório}

A pesquisa das fontes resultou em uma lista extensa, a qual foi organizada, dividida e estruturada, inicialmente, nas seguintes facetas: "Artigos científicos", "Bases de preprints", "Teses e Dissertações" e "Dados de pesquisa". Contudo, percebeu-se que diversas fontes continham informações de mais de uma tipologia, levando à criação da categoria "Agregadores de informação científica", para fontes que dispunham de mais de um tipo de informação. Por fim, também foi percebido que algumas das fontes selecionadas continham informações que não se encaixavam nas categorias já estabelecidas, por possuírem um teor mais técnico, sendo criada a última categoria, "Relatórios e evidências". De posse da lista das fontes e definidas as facetas, foi feita uma deduplicação ${ }^{5}$ das fontes obtidas e, por fim, elaborados textos descritivos e informativos sobre cada um.

A navegação e estrutura do Diretório foi organizada em facetas, definidas a partir dos diferentes tipos de fontes de informação levantadas, sendo elas:

a) Artigos científicos: artigos científicos relacionados à temática;

b) Teses e dissertações: portais que reúnem Teses e Dissertações de várias instituições e países;

c) Dados de pesquisa: dados de pesquisa relacionados ao Covid-19, em especial os presentes nos repositórios de dados;

d) Bases de preprints: bases de manuscritos de artigos científicos que ainda não foram publicados em revistas científicas;

e) Agregadores de informação científica: plataformas onde podem ser encontrados diversos tipos de fontes reunidas em único local; e

f) Relatórios e evidências: publicações que trazem protocolos clínicos baseados em evidências.

Ressalta-se que a repercussão do Diretório traz índices de acessos relevantes, desde seu lançamento, que pode ser comprovado nos resultados apresentados neste relato. Dada a repercussão mundial, o Diretório teve todo seu conteúdo traduzido para dois idiomas, o inglês e o espanhol, o que facilita ainda mais sua difusão.

\section{Implementação do Diretório}

No início do processo de desenvolvimento do Diretório, surgiu a questão sobre qual seria a melhor ferramenta disponível no momento para desenvolvê-lo. Para a implementação do Diretório optou-se pela ferramenta WordPress ${ }^{6}$, plataforma de gestão de informação em código aberto desenvolvida na linguagem PHP. Esta decisão

\footnotetext{
${ }_{5}^{5}$ Procedimento em que um conjunto de dados/informações é verificado e possíveis duplicidades são removidas.

${ }^{6}$ Disponível em <https://br.wordpress.com/>
} 
foi tomada com base na experiência no uso e implementação desta ferramenta, que foi utilizada em projetos anteriores oriundos da mesma equipe. Após a instalação foram feitas alterações no layout mediante o uso do template $\mathrm{Hello}^{7}$ e o plugin Elementor page-builder ${ }^{8}$, um construtor de páginas que oferece modelos de seção prémoldados e que permite a edição e visualização das alterações em tempo real.

No que diz respeito à tradução dos conteúdos do Diretório, foi utilizado o plugin Polylang 9 , que possibilita que cada tradução seja inserida manualmente. Com ele, é possível criar versões traduzidas das páginas, das postagens, das categorias e menus, fazendo com que tenha sido possível, também, a criação de réplicas traduzidas do Diretório.

O conteúdo das páginas internas de cada fonte foi organizado em ordem alfabética e inserido em caixas com efeito acordeão. Esse efeito tem a finalidade de otimizar o espaço da página, pois o conteúdo somente é apresentado quando se clica na seção. Dessa forma, foi possível apresentar mais de 40 fontes de uma mesma tipologia, sem demandar muito espaço na página, deixando-a visualmente limpa e possibilitando uma utilização mais dinâmica. Ao final da página inicial, logo acima do rodapé, foram inseridos dois banners, os quais fazem referência e dão acesso aos outros dois sistemas que compõem este relato, o Repositório de preprints EmeRI e a Rede de Especialistas e Pesquisas.

\section{EMERGING RESEARCH INFORMATION (EMERI)}

As discussões acerca da utilização de preprints (também conhecidos como manuscritos enviados para uma revista, que não passaram pela avaliação por pares) na comunicação científica têm sido frequentes e conduzidas por pesquisadores de todo o mundo e das mais diversas áreas do conhecimento. $O$ interesse mais recente da comunidade científica em se debruçar sobre o tema tem sido notório e pode ser explicado por duas principais questões: a ascensão da Ciência Aberta, que pressupõe um fazer científico mais transparente e colaborativo, e a pandemia causada pelo novo coronavírus, que colocou os cientistas, especialmente aqueles vinculados às áreas da saúde, frente a uma emergência sanitária global sem precedentes.

Apesar deste contexto ora apresentado, não se pode dizer que a necessidade de disponibilização de preprints seja uma demanda de fato atual, somente que se tornou ainda mais latente. Acerca do principal motivo para a adoção desse tipo de publicação, Spinak (2019) aponta que "[...] é o estabelecimento da precedência de descobertas, a diminuição do tempo para comunicar os resultados de pesquisa e a oportunidade de receber comentários e feedback sobre o trabalho depositado no servidor" (SPINAK, 2019, n. p.). Percebe-se, assim, que a disponibilização de preprints traz uma série de benefícios para a construção do conhecimento científico, fazendo com que outras iniciativas sejam repensadas e que aquelas já existentes possam ser aperfeiçoadas.

O Repositório de preprints Emerging Research Information (EmeRI) é uma das iniciativas brasileiras que visa, além de dar suporte à criação de uma estrutura para a implementação da Ciência Aberta no Brasil, fomentar a disseminação, ampliar o acesso e acelerar a disponibilização da produção científica submetida às revistas científicas

\footnotetext{
7 Disponível em <https://wordpress.org/themes/hello-elementor/>

${ }^{8}$ Disponível em <https://wordpress.org/plugins/elementor/>

9 Disponível em <https://br.wordpress.org/plugins/polylang/>
} 
brasileiras, inclusive aquelas que dizem respeito à pandemia causada pelo novo coronavírus.

A criação do EmeRI é resultado da parceria entre a Associação Brasileira de Editores Científicos (Abec) e o lbict, com apoio da Organização das Nações Unidas para a Educação, a Ciência e a Cultura (UNESCO). O Repositório EmeRI se assemelha a outras iniciativas já existentes, entretanto se diferencia das demais por sua forma de gerenciamento, onde são as revistas que depositam os preprints a elas submetidos, e não os próprios autores. Além da diferenciação no que diz respeito ao gerenciamento, o EmeRI também foi arquitetado de modo a não se restringir às revistas brasileiras ou latino-americanas. Sendo assim, revistas editadas por qualquer país do mundo podem ser nele indexadas, com a única restrição de que cumpram os pré-requisitos definidos. Não obstante, uma das ideias que permeou a criação do EmeRI foi oferecer à comunidade científica mundial um espaço para a publicação de preprints, trazendo assim uma maior visibilidade dos resultados de pesquisa, como também das próprias revistas.

\section{Aspectos informacionais}

Um dos primeiros aspectos considerados no início da construção do EmeRI foi sobre como seriam validados os preprints ali depositados, uma vez que há, no âmbito da comunidade científica, diversos questionamentos sobre a cientificidade e autenticidade dessas publicações. Tradicionalmente, o depósito é realizado pelo próprio autor, e a validação do documento é realizada pela própria equipe do repositório, ou, em alguns casos, sequer é realizada. Com vistas a encontrar uma melhor solução para esta questão, optou-se por delegar a avaliação de conformidade para as revistas científicas, dado que já possuem uma equipe de editores especializados em suas respectivas áreas e que usualmente já fazem essa atividade, conhecida como desk review.

Deste modo, a solução encontrada pela equipe responsável pela definição da estrutura informacional do EmeRI foi de criar o repositório para as revistas científicas, e não para os autores. Na prática, significa dizer que a responsabilidade pelo depósito é dos editores científicos, e não dos autores. A adoção desta metodologia tem impacto direto no rigor científico do repositório, uma vez que os editores são obrigados, antes de depositar um preprint, fazer uma revisão preliminar de conteúdo e forma daquele documento, assegurando que, apesar de ainda não ter sido avaliado, ele já foi aceito para o processo formal de revisão por pares.

Sendo assim, uma das primeiras atividades foi a redação da política informacional do repositório, uma vez que este documento é responsável por reger todo seu funcionamento. Com a redação da política, foram definidas competências e atribuições para todas as partes envolvidas no EmeRI, bem como os pré-requisitos às revistas científicas que desejem ser indexadas, sendo elas:

a) Ser de caráter acadêmico/científica;

b) Ter registro de ISSN;

C) Comprometer-se a depositar ao menos 12 preprints nos primeiros doze meses de indexação, 18 nos doze meses subsequentes e 24 a cada doze meses, daí em diante; 
d) Não ser publicada por uma editora listada como possivelmente predatória no site Stop Predatory Journals ${ }^{10}$, nem integrar a lista de revistas possivelmente predatórias, identificadas neste site;

e) Estar indexada em ao menos um indexador, temático ou universal, que exija, ao menos, os requisitos necessários para integrar o DOAJ; e

f) Estar de acordo com a Licença de distribuição formulada pelo EmeRI.

Esses pré-requisitos foram definidos para auxiliarem na comprovação do caráter científico/acadêmico da revista, para uma avaliação mínima de sua qualidade editorial e de credibilidade dos conteúdos publicados, bem como para a declaração dos direitos de uso do preprint depositado no EmeRI.

Especificamente sobre os direitos de uso, os editores devem declarar que concedem uma licença Creative Commons BY NC para o EmeRI. A atribuição desta Licença implica que o preprint será disponibilizado em acesso totalmente aberto no EmeRI, que a informação contida nele não pode ser explorada comercialmente sem autorização explícita e que qualquer uso que dela seja feito deve necessariamente creditar seus autores e autoras. A concessão desta licença dá ao EmeRI o direito não-exclusivo de reproduzir, traduzir, e/ou distribuir o preprint, em qualquer meio ou formato (impresso ou eletrônico, incluindo áudio ou vídeo).

A próxima etapa foi voltada à elaboração dos metadados do EmeRI, onde foi utilizado o padrão Dublin Core. O padrão foi criado por colaboradores da Abec e do Ibict, todos com experiência prática de trabalho com revistas científicas. Nesta etapa foi decidido que, com vistas a melhor internacionalização do repositório, ele teria de ser multilíngue, operando nos seguintes idiomas: Português, Inglês, Francês e Espanhol. Assim sendo, foi feita a descrição desses metadados para cada um dos idiomas listados acima. A primeira versão do padrão de metadados do EmeRI foi finalizada com 20 metadados, os quais descrevem tanto as revistas quanto os preprints.

\section{Implementação do Repositório}

Para o desenvolvimento do repositório foi escolhido o software de código aberto DSpace ${ }^{11}$, versão 6.3, que fornece facilidades para o gerenciamento de acervo digital. O EmeRI segue a estrutura hierárquica do DSpace, composta de Comunidades, Subcomunidades, Coleções e Itens. Deste modo, definiu-se que o nível "Comunidade" seria "Scientific journals" e que não seria necessária a utilização do nível "Subcomunidade". O terceiro nível, "Coleções", foi criado para que os responsáveis diretos pelas revistas pudessem gerenciá-las à medida que forem indexadas. Por fim, o quarto nível, "Itens", que é o nível mais específico dentro da estrutura do DSpace, é onde os preprints são, de fato, descritos e depositados.

O próximo passo foi a criação e implementação do padrão de metadados, onde foi utilizado o arquivo de configuração input-forms.xml. É válido ressaltar que a criação e implementação do padrão de metadados precisou ser replicada quatro vezes, dado que o EmeRI é um repositório multilíngue. As customizações de layout foram feitas com base nas páginas JavaServer Pages, uma tecnologia que mescla a linguagem de programação java com HTML e XML. Foram feitas também customizações nas cores,

\footnotetext{
${ }^{10}$ Disponível em: <https://predatoryjournals.com/>

${ }^{11}$ Disponível em: <https://duraspace.org/dspace/>
} 
estilos e fontes, utilizando o framework web Bootstrap que possui código-fonte aberto para desenvolvimento de componentes de interface e front-end para sites e aplicações web usando HTML, CSS e JavaScript.

A última etapa do projeto-piloto do EmeRI se deu com a elaboração dos documentos administrativos do repositório. Assim sendo, foram redigidos os seguintes documentos: "Licença de distribuição não exclusiva", "Declaração de revisão preliminar" e "Perguntas frequentes". Além disso, também foi criada a template, que deve ser utilizada pelas revistas quando da submissão de um preprint.

Finalizada a implementação, o EmeRI foi lançado oficialmente, durante dois eventos: um promovido pela Abec e outro pelo Ministério de Ciência, Tecnologia e Inovações $(\mathrm{MCTI})$. A partir de então, iniciou-se a divulgação do repositório, bem como a indexação de novas revistas.

A indexação de revistas é feita a partir da solicitação de seus respectivos editores e/ou equipes editoriais. Ao tomar conhecimento dos pré-requisitos e estar de acordo a política informacional do EmeRI, compete aos editores e/ou equipes editoriais o preenchimento do formulário de cadastro que se encontra na página inicial da plataforma, informando dados básicos da revista e, em seguida, fazer o registro do usuário, indicando login e senha para acesso. De posse dos dados, os administradores do repositório criam a coleção referente à revista e fornecem ao editor a permissão de depositar os preprints associados a sua revista. Concluída esta etapa, o depósito de preprint ocorre mediante acesso do editor científico ao ambiente interno do EmeRI.

\section{REDE DE ESPECIALISTAS E PESQUISAS}

A colaboração científica é definida pela ação de dois ou mais pesquisadores e/ou grupos de pesquisa com um objetivo comum de alcançar resultados em uma determinada área de pesquisa. Pode-se dizer que esta atividade é frequente em todas as áreas do conhecimento, decorrente da impossibilidade de se fazer ciência isoladamente.

Em especial na área da saúde, a colaboração entre pesquisadores se torna latente, dada a necessidade do alcance rápido de resultados em resposta a questões como as que estão estabelecidas pela atual pandemia de Covid-19. A busca por tratamentos adequados e imunizadores sobre o novo coronavírus realçam a necessidade de colaboração científica nos níveis nacional, regional e internacional. O novo coronavírus tem como uma de suas características o comportamento distinto, inclusive em regiões geograficamente próximas, fazendo com que as redes de colaboração científica sejam estritamente necessárias no alcance de resultados concretos no combate da doença.

Diante deste panorama, uma das iniciativas desenvolvidas pelo lbict, em parceria com a Fundação Oswaldo Cruz (Fiocruz), foi a identificação de pesquisadores brasileiros com a produção científica declarada no Currículo Lattes ${ }^{12}$ sobre os temas "Coronavírus", "Síndrome respiratória aguda grave" e "Covid-19". O conjunto de currículos de 1.370 pesquisadores identificados foi o insumo que levou à construção da plataforma Rede de Especialistas e Pesquisas ora apresentada.

A plataforma recebeu curadoria do pesquisador Fábio Gouveia (Fiocruz) e foi desenvolvida a partir do uso da ferramenta ScriptLattes (MENA-CHALCO; CESAR JR,

${ }^{12}$ Disponível em <http://lattes.cnpq.br/> 
2009). Entre as ações de curadoria executadas, estiveram a aplicação de filtros e limpeza dos dados coletados, tendo por princípio a seleção da produção científica que tratava dos temas específicos pré-definidos. Estas ações de curadoria não são realizadas automaticamente, exigem particular dedicação da equipe executora. Contudo, são fundamentais para a correta seleção dos resultados de pesquisa afetos à temática proposta.

O objetivo principal da Rede de Especialistas e Pesquisas é de apresentar as redes de colaboração existentes entre pesquisadores e suas respectivas produções científicas sobre a temática definida. A ferramenta pode ser utilizada com diversos fins, entre eles se sobressai o de servir como insumo para o estabelecimento de novas colaborações entre pesquisadores, de modo a aprofundar pesquisas e acelerar resultados no combate à pandemia.

\section{Aspectos informacionais}

Nas redes de colaboração científica é realizado o agrupamento da produção científica dos pesquisadores selecionados. Essa produção científica conta com artigos científicos; relatórios de pesquisas; teses; dissertações; relatórios de pós-doutorado; livros; capítulos de livro; artigos apresentados em eventos; etc. Para além da produção científica, são também agrupadas as orientações de doutorado, mestrado, trabalho de conclusão de curso de graduação e iniciação científica. Orientações estas que estão classificadas como "em andamento" ou "concluídas".

Com base nas relações de coautoria da produção científica agrupada é possível estabelecer as redes de colaboração, as quais podem ser exibidas no formato de um grafo de nós e arestas que representam, respectivamente, os pesquisadores e suas colaborações (Figura 1). Exemplificando, se há uma aresta ligando o nó do "Pesquisador 1" ao nó do "Pesquisador 2", esta representação traduz o fato de que os dois pesquisadores são coautores em uma publicação. Para além da exibição das redes, é também estabelecida uma medida de colaboração, tendo como base métrica PageRank (PAGE, 1998).

São enumeradas abaixo as demais visualizações obtidas com os dados agregados:

a) Mapa de geolocalização que apresenta a localização por latitude e longitude dos pesquisadores, com base nas instituições declaradas como endereço profissional de seus respectivos currículos (Figura 2);

b) Gráficos quantitativos por ano da produção científica e demais itens agregados à Plataforma (Figuras 3 à 5);

c) Lista dos pesquisadores selecionados com seus respectivos quantitativos de produção agregada e informações adicionais, tais como: grande área; área de atuação; segundo tabela de classificação de áreas do conhecimento do CNPq13.

\section{Implementação da Rede}

O relatório pós-curadoria gerado pela ferramenta ScriptLattes foi desmembrado e adicionado à uma instância do sistema WordPress. A escolha desta ferramenta para

${ }^{13}$ Disponível em <http://www.cnpq.br/documents/10157/186158/TabeladeAreasdoConhecimento.pdf> 
criação do portal, onde a Rede foi implementada, teve como motivação a facilidade de seu uso, instalação e configuração. Em especial, a visualização interativa das redes de colaboração foi obtida por meio da criação de uma interface construída na linguagem $\mathrm{R}$, com o uso da biblioteca Shiny ${ }^{14}$.

\section{RESULTADOS E DISCUSSÕES}

Esta seção traz, individualmente, dados provenientes dos três sistemas relatados. Optou-se por apresentá-las nesta estrutura, pois, apesar de terem sido desenvolvidas em um mesmo contexto, trazem dados e informações peculiares, carecendo, portanto, de ponderações distintas.

\section{Diretório de fontes}

O Diretório de fontes de informação científica de livre acesso sobre o Coronavírus conta, atualmente, com 6 categorizações e facetas, sendo elas: Artigos científicos (32 fontes), Teses e Dissertações ( 2 fontes), Dados de pesquisa (13 fontes), Bases de preprints ( 8 fontes), Agregadores de informação científica (31 fontes) e Relatórios e evidências ( 8 fontes). Perfazendo um total de 94 fontes de informações científicas, sendo que todas possuem publicações que tratam do novo coronavírus, ainda que em proporções diferentes. A distribuição proporcional das fontes dentro do Diretório pode ser melhor visualizada no Gráfico 1.

\section{Gráfico 1 - Gráfico da distribuição das fontes no Diretório}

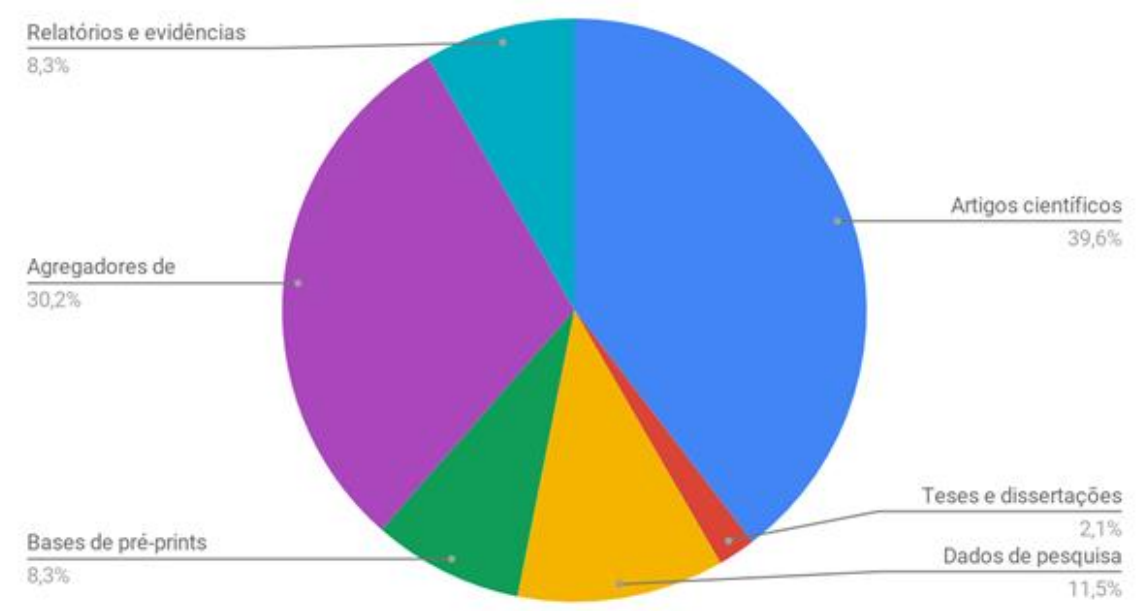

Fonte: Elaboração própria.

Ressalta-se que todas as fontes do Diretório estão em constante atualização. Isso é necessário uma vez que, algumas delas, especialmente as que constam na categoria "Artigos científicos", não são usualmente de acesso aberto, uma vez que as editoras que as detém somente disponibilizaram alguns de seus periódicos sobre o tema

${ }^{14}$ Disponível em: <https://shiny.rstudio.com/> 
durante determinado período de tempo. Deste modo, faz-se necessária uma constante checagem e reavaliação.

No que tange ao alcance do conteúdo disponibilizado no Diretório, ele pode ser quantificado por meio do número de visualizações à página e, principalmente, pelo local de origem dos acessos. Para o monitoramento desse alcance, utiliza-se o Google Analytics, dado que sua implementação é de fácil entendimento e a plataforma já fornece diversas informações sobre a utilização da página, como a quantidade de acessos, o local de origem do usuário, média do número de acessos, registro do horário dos acessos, etc.

O Diretório vem sendo acessado por diversos países, com um total de mais de 11.159 acessos desde seu lançamento, em 02/04/2020, com a média aproximada de 83 acessos por dia, até 14/08/2020, data em que os resultados foram consolidados. Os acessos são, em sua maioria, do Brasil, que representa $82,41 \%$ do total. A Espanha responde por 2,94\% e a Argentina por 2,68\%. Os demais acessos são provenientes dos Estados Unidos, México, Peru, Portugal, Austrália, Chile e Colômbia.

Os dados apresentam resultados que demonstram a necessidade de realização de uma estratégia de divulgação efetiva, o que pode ser contornado a curto, médio e longo prazo.

\section{Emerging Research Information (EmeRI)}

De acordo com os dados das revistas apresentados no EmeRI, a indexação das revistas teve seu início em meados de Abril de 2020, com o aceite da publicação "Revista Brasileira de Psicodrama (Online)" e "Ciência da Informação (Online)", e o primeiro depósito de preprint ocorreu no dia 22 do mesmo mês. Até o momento, 11 revistas solicitaram indexação no repositório, e apenas 9 cumpriram os pré-requisitos estabelecidos. As revistas que não foram inicialmente aprovadas podem, a partir do momento que cumprirem os requisitos, solicitar, novamente, a indexação. Das 9 revistas cadastradas no EmeRI, apenas 4 depositaram preprints até o presente momento, totalizando 15 preprints. As demais, apesar de já terem encaminhado os arquivos, estão passando pelo processo de formatação e diagramação, para então serem depositados.

Das revistas indexadas até então, 8 são brasileiras e 1 é equatoriana. No que diz respeito às áreas temáticas, elas cobrem: Ciência da Informação, Comunicação social, Educação, Medicina, Enfermagem, Odontologia, Direito e Psicologia. Já em relação às áreas temáticas dos preprints, elas são mais diversas, já que a área de cada revista se subdivide em temáticas específicas. Contudo, se destacam os trabalhos que dizem respeito ao novo coronavírus, uma vez que 6 dos 15 preprints depositados possuem relação com o tema. Por fim, em relação ao idioma dos preprints, 8 são em português, 5 em inglês e 2 em espanhol.

No EmeRI também é utilizado o Google Analytics, mas o início da contagem se deu somente no dia 11/05/2020. Até a data de fechamento dos dados, 14/08/2020, obtevese um total de 17.514 visualizações realizados por 1.454 usuários distintos, gerando uma média aproximada de 182 acessos diários. Dos 1.454 usuários que acessaram o Repositório, $60,32 \%$ são do Brasil e $27,85 \%$ são de países que não foram identificados pelo Google Analytics. A plataforma foi acessada, também, por usuários dos Estados Unidos, Peru, Equador, Colômbia, Espanha, Argentina, França e Reino Unido. 
Não há dúvidas que tal iniciativa necessita ainda de uma maior divulgação nos meios editoriais, nacionais e internacionais, para que o EmeRI seja amplamente conhecido e utilizado.

\section{Rede de Especialistas e Pesquisas}

A primeira visualização exibida na Rede são os grafos de colaboração (Figura 1). Nesta interface, o grafo exibido permite a aplicação de filtros que selecionam os nós e arestas a serem exibidas, de acordo com os rótulos "Doutor", "Doutor com grupo de pesquisa", "Não Doutor" e "Não Doutor com grupo de pesquisa". Ainda é possível aplicar um filtro de exibição, de acordo com o índice de colaboração de cada pesquisador, utilizando-se a métrica PageRank. A exibição do tamanho dos nós é proporcional ao índice de colaboração exibido pelo pesquisador correspondente, enquanto a coloração dos nós é determinada pela classificação "Doutor", "Doutor com grupo de pesquisa", etc.

Ao se realizar o clique uma única vez em um determinado nó, exibe-se o nome do pesquisador correspondente, e ao se realizar dois cliques é possível acessar o Currículo Lattes do pesquisador.

Figura 1 - Grafo da rede de pesquisadores sobre Coronavírus, SRAG e Covid-19

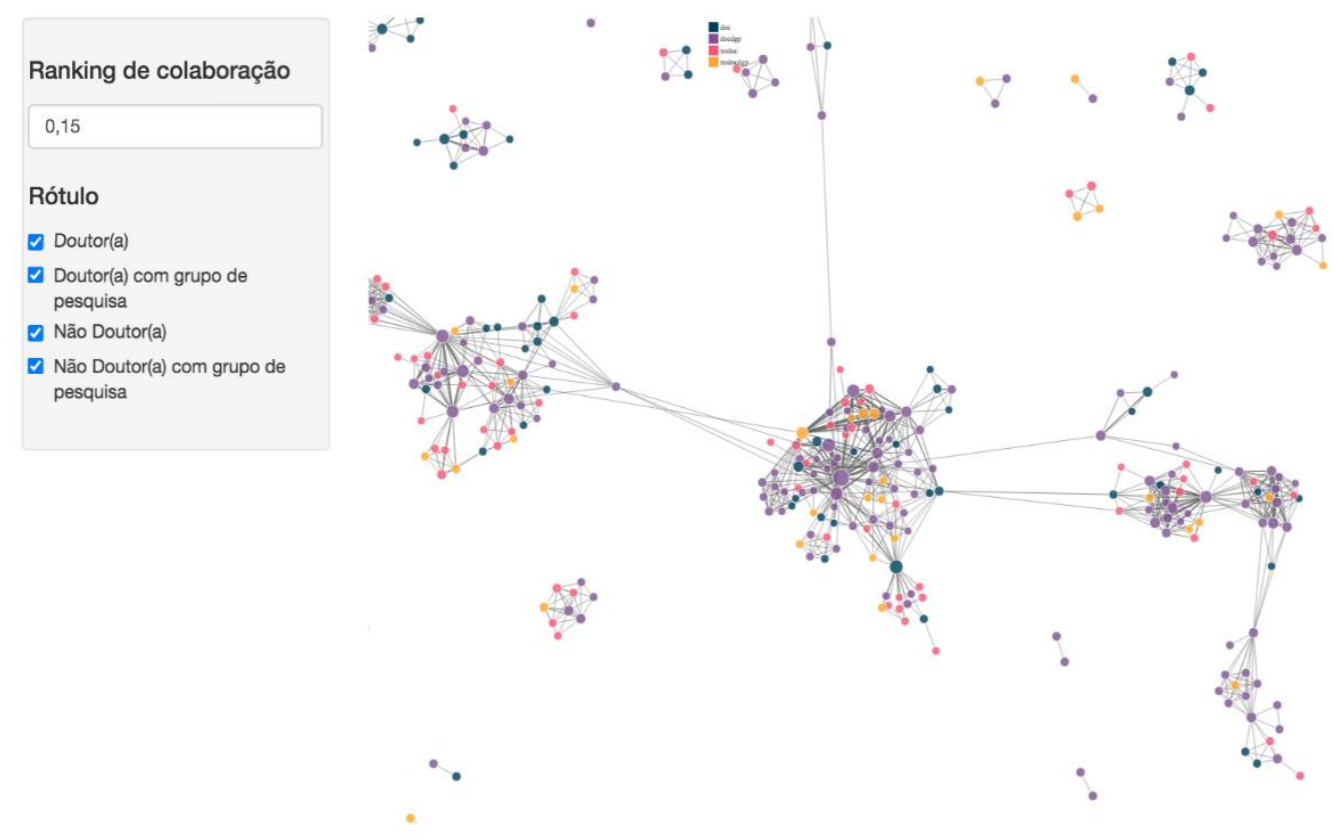

Fonte: Elaboração própria.

Também, conforme já mencionado, o mapa de geolocalização (Figura 2) exibe a distribuição geográfica dos pesquisadores, de acordo com o endereço profissional declarado nos seus respectivos currículos. Ao se realizar um clique no marcador do pesquisador, é exibida uma imagem com a foto deste e um link para o seu respectivo Currículo Lattes. 
Figura 2 - Mapa interativo com a localização das instituições

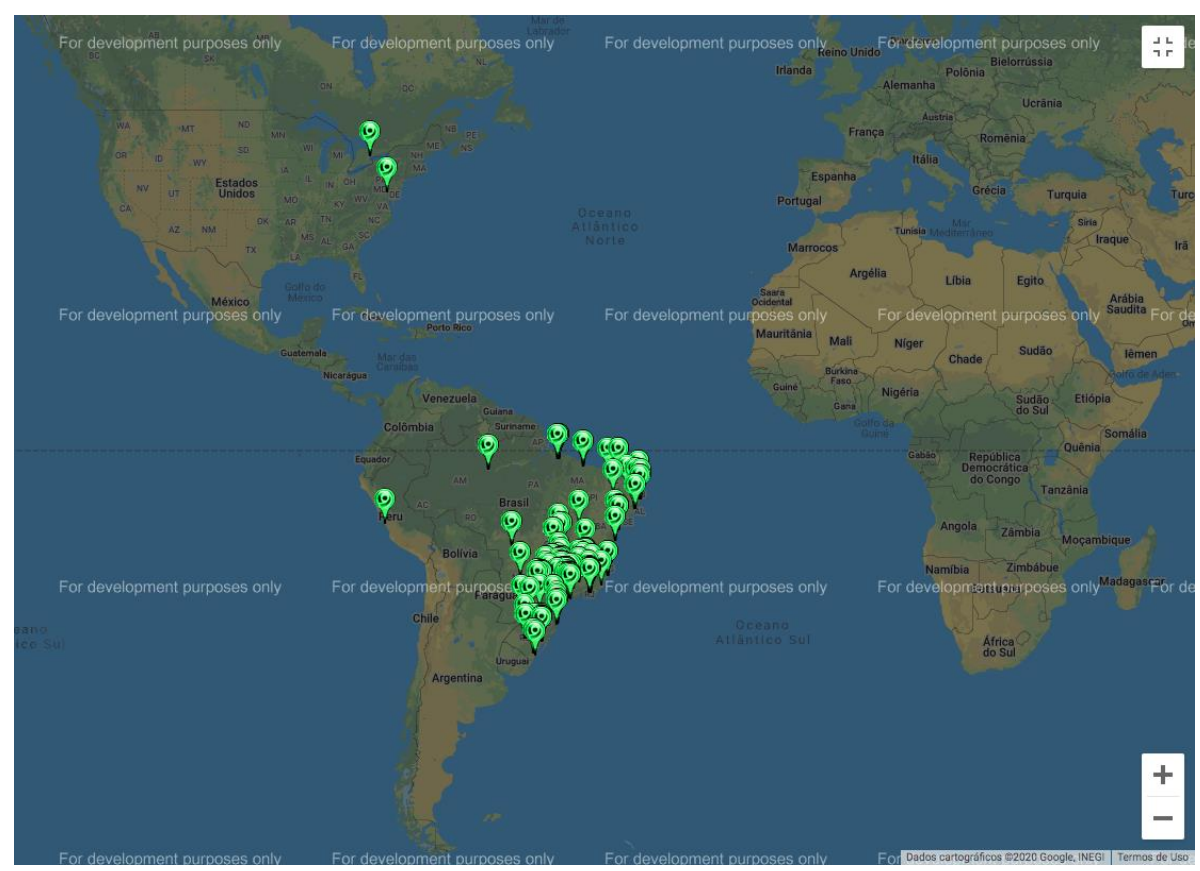

Fonte: Elaboração própria.

Os gráficos de Produção Bibliográfica, Produção Técnica, Orientações e Supervisões apresentam os quantitativos por ano de cada agrupamento. Estas visualizações permitem que pesquisadores encontrem com mais rapidez as produções de seus pares. Os gráficos da Figura 3, Figura 4 e Figura 5 apresentam "Artigos completos publicados em periódicos", "Apresentações de trabalho" e "Projetos de pesquisa", respectivamente.

Figura 3 - Gráficos de quantidade de artigos publicados em periódicos por ano.

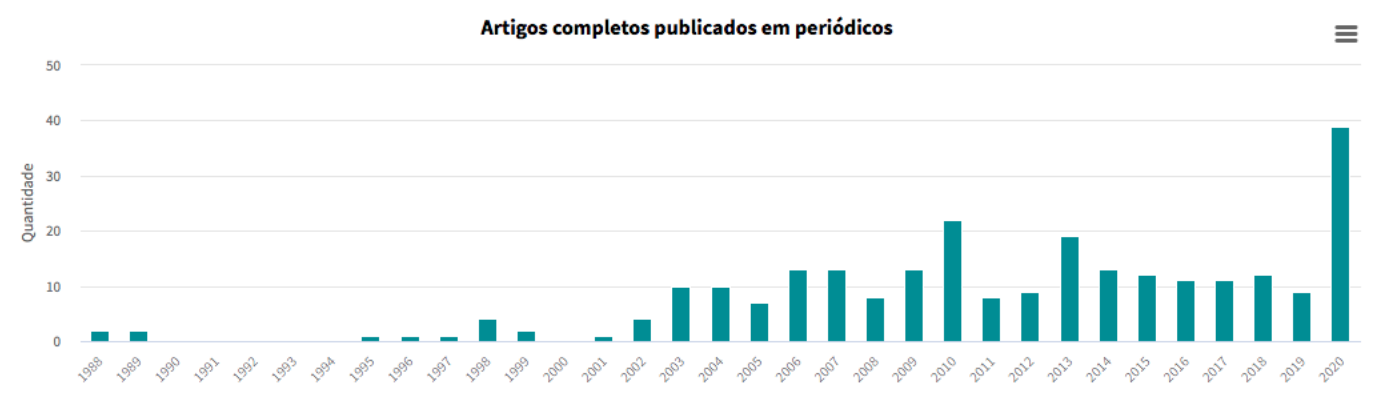

Fonte: Elaboração própria. 
Figura 4 - Gráficos da quantidade de apresentação de trabalhos por ano.

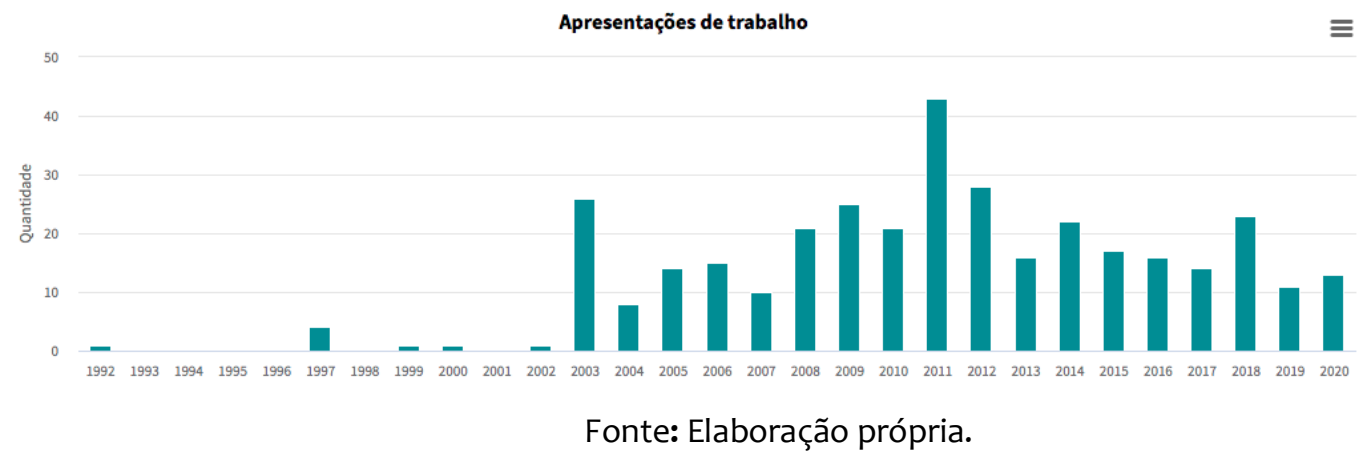

Figura 5 - Gráficos de quantidade de projetos de pesquisa por ano.

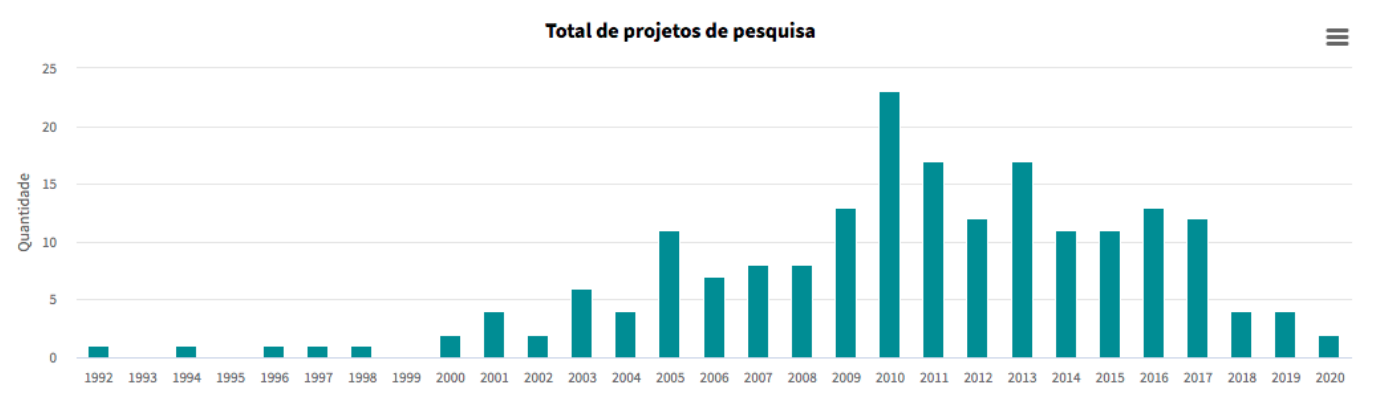

Fonte: Elaboração própria.

Semelhante aos gráficos acima, também é possível visualizar na Rede diversos outros dados das produções científicas dos pesquisadores levantados, tais como: artigos aceitos para publicação, resumos publicados em anais de congressos, resumos expandidos publicados em anais de congressos, capítulos de livros publicados, livros publicados, trabalhos completos, produtos tecnológicos, processos ou técnicas, teses de doutorado, dissertações de mestrado e trabalhos de conclusão de curso de graduação.

A Rede de Especialistas e Pesquisas também tem o seu acesso monitorado por meio do uso da ferramenta Google Analytics. O início do controle foi em 05/04/2020. Até a data de fechamento dos dados, 14/08/2020, obteve-se um total de 7.173 visualizações realizadas por 934 usuários distintos, gerando uma média aproximada de 55 acessos diários. Dos 934 usuários que acessaram a Rede, 79,68\% são do Brasil. Um número inferior a 2\% é dos Estados Unidos, Argentina, Equador, Colômbia, Peru, Espanha e Reino Unido. As demais visualizações são provenientes de países não identificados pela plataforma de controle de acesso.

\section{CONSIDERAÇÕES FINAIS}

Os três sistemas relatados neste estudo são resultantes de ações coordenadas e desenvolvidas pelo Ibict em meio a pandemia causada pelo novo coronavírus, e todas elas tiveram apoio e/ou parceria com outras instituições, onde se destacam: a Unesco 
Representação Brasil (nas iniciativas do Diretório e Repositório EmeRI), a Abec e Fiocruz (no caso do EmeRI e da Rede de Especialistas, respectivamente), e o Grupo de pesquisa "Gestão da informação e do conhecimento", da Universidade Federal do Amazonas (UFAM) (no caso do Diretório de fontes).

Cada uma das ações possui suas especificidades, mas se integram no sentido de prover informações de caráter científico e tecnológico que podem servir de insumo para políticas públicas de combate à pandemia.

O Diretório de fontes foi a primeira ação colocada em desenvolvimento. Um dos pontos de partida que levou à construção do Diretório foi, além do compromisso histórico do Ibict com os Movimentos de Acesso Aberto e de Ciência Aberta, a liberação de vários artigos por parte de editoras científicas comerciais, que decidiram por período determinado, dar livre acesso a parte de suas coleções, especialmente aquelas que tratavam de conteúdos científicos sobre o novo coronavírus. Ainda não se sabe qual será a postura adotada por essas editoras comerciais ao fim da pandemia, mas a iniciativa de liberar parte de suas coleções traça um cenário promissor em relação à consolidação do Acesso Aberto e da Ciência Aberta.

Logo após seu lançamento, o Diretório foi divulgado por meio de diferentes canais de comunicação, como fóruns especializados, Institutos de Pesquisa, Órgãos e Instituições da área de saúde, páginas de notícias de centros de informação, jornais, seminários, simpósios e workshops on-line. Esta divulgação foi essencial e trouxe visibilidade ao Diretório, proporcionando a quantidade de acessos relatada. Contudo, o planejamento de novas ações de divulgação é necessário para que seu alcance seja mais efetivo.

Além da questão da divulgação, outro problema enfrentado na gestão do Diretório diz respeito às fontes que o compõe, que demonstra ser uma tarefa árdua. Acredita-se que a tendência é que o número de fontes disponíveis em livre acesso entre em decréscimo, dado que boa parte das fontes que compõem o Diretório são de editoras comerciais. Caso tal hipótese se confirme, as fontes serão retiradas do Diretório, o que invariavelmente implicará na redução dos acessos diários.

Se por um lado o desafio enfrentado pela equipe do Diretório de fontes se concentra na não redução do número de fontes disponíveis, a equipe do EmeRI apresenta um desafio relativamente distinto, que é o aumento do número de revistas científicas indexadas. Tal desafio tem relação com os ideais trazidos pelo Movimento da Ciência Aberta, nesse caso em específico, a adoção à publicação de preprints.

A resistência que se percebe por parte de alguns editores e equipes editoriais é ancorada à questões históricas que permeiam o universo da comunicação e da editoração científica e que talvez ainda não estejam bem esclarecidas. Dentre elas: a questão da exigência de originalidade e ineditismo nas publicações, conflitos referentes a direitos autorais, receio de se depositar uma pesquisa ainda não avaliada por pares em um repositório de acesso aberto, etc.

A título de exemplificação, alguns editores entraram em contato com a equipe do EmeRI indicando que a adoção da modalidade de avaliação por pares duplo-cega pode gerar alguns problemas para o depósito dos preprints. A partir do momento em que um preprint está depositado em um repositório de acesso aberto, que é o caso do EmeRI, a identidade do autor é revelada, e, assim, os futuros avaliadores daquele preprint podem reconhecer a autoria, descaracterizando a modalidade duplo-cega de avaliação. Um dos modos de resolver tal questão seria, no ato da submissão de um artigo para uma revista indexada no EmeRI, o autor ser questionado tanto da possibilidade do artigo ser avaliado em modalidade aberta, para que não haja 
problemas em relação à avaliação, quanto da permissão de depósito da versão preprint no EmeRI. Contudo, para que tais questões sejam implementadas, há necessidade de revisão e alteração da política editorial da revista, demandando planejamento por parte da equipe responsável.

Além dessas questões técnicas, há de se considerar que o trabalho realizado pelos editores científicos brasileiros geralmente é acumulado com outras funções, fazendo com que o conhecimento acerca de novas plataformas de indexação, bem como os critérios requisitados por cada uma delas, nem sempre esteja dentre as pautas prioritárias.

Apesar desses pontos elencados acima, algumas conclusões preliminares e positivas podem ser obtidas a partir desses meses em que o EmeRI está em operação. A primeira delas é a abrangência temática das revistas indexadas, já que não se percebe a concentração de áreas do conhecimento e nem de enfoque tão similares dos preprints depositados. A segunda, é a diversidade linguística dos preprints depositados, o que denota um esforço e preocupação dos autores em relação à internacionalização de suas pesquisas, que acaba sendo maior à medida que se publica não somente no idioma nativo (no caso, o português). A terceira questão diz respeito à quantidade de preprints sobre a temática do novo coronavírus (pouco mais de $1 / 3$, um terço, do total), demonstrando que o EmeRI proporciona, dentro de suas limitações quantitativas, celeridade na disponibilização e acesso a essas pesquisas, provenientes da emergência sanitária causada pela pandemia.

No caso da Rede de Especialistas e Pesquisas, observa-se que um dos pontos críticos da construção da Plataforma é a atualização dos dados exibidos. Estes são selecionados por meio da identificação de pesquisadores e da curadoria da produção científica a ser agregada à base. Sendo esta uma tarefa que exige execução manual, tem-se por trabalho futuro o desenvolvimento de procedimentos que automatizem esse processo, tendo por objetivo final a manutenção sustentável da Plataforma.

É necessário também considerar que a descrição das visualizações de dados apresentadas deve ser aprimorada para a ampliação do público alvo. Este público não deve se restringir aos conhecedores da área de cientometria e de ciência de dados. Ademais, deve-se considerar como trabalho futuro a realização de estudo mais aprofundado sobre as possíveis visualizações que devem ser construídas a partir dos dados obtidos do Currículo Lattes e seus possíveis cruzamentos com outras fontes de informação, tais como a Biblioteca Digital Brasileira de Teses e Dissertações (BDTD) ${ }^{15} \mathrm{e}$ o Portal Brasileiro de Publicações Científicas em Acesso Aberto (oasisbr) ${ }^{16}$.

Os três sistemas aqui relatados, criados e mantidos pelo lbict com o apoio de outras instituições, somam, no total, 35.846 visualizações, dados do início do monitoramento até o dia 14/08/2020. Esses acessos extrapolam as fronteiras do Brasil e provém de diversos outros países, fazendo com que pesquisas, pesquisadores, métodos, experimentos, etc., estejam todos interligados, aumentando consideravelmente o nível de colaboração científica das pesquisas que versam sobre a pandemia causada pelo novo coronavírus.

Com vistas a finalização deste relato, fica evidente que os movimentos de Acesso Aberto e Ciência Aberta, se antes não estavam na pauta da comunidade científica mundial, passaram a estar. Resta saber se, de modo definitivo, a comunicação científica

\footnotetext{
${ }^{15}$ Disponível em: <http://bdtd.ibict.br>

${ }^{16}$ Disponível em: <http://oasisbr.ibict.br>
} 
adotará essas novas práticas de se fazer e compartilhar a Ciência, de modo fluído, como o bem comum que é, livre de barreiras econômicas.

\section{REFERÊNCIAS}

MENA-CHALCO, Jesús P.; CESAR JUNIOR, Roberto Marcondes. Prospecção de dados acadêmicos de currículos Lattes através de scriptLattes. Bibliometria e Cientometria: reflexões teóricas e interfaces. São Carlos: Pedro \& João, 2013. Disponível em: https://www.researchgate.net/publication/280113692. Acesso em: 14 ago. 2020.

PAGE, Lawrence et al. The PageRank citation ranking: bringing order to the web. [S.I.]: Stanford InfoLab, 1998. Disponível em: http://ilpubs.stanford.edu:809o/422/1/199966.pdf. Acesso em: 14 ago. 2020.

SPINAK, Ernesto. Acelerando a comunicação científica via preprints. SciELO em Perspectiva, 2019. Disponível em: https://blog.scielo.org/blog/2019/10/04/acelerando-acomunicacao-cientifica-via-preprints/\#.XoO--8hKjlU. Acesso em: 14 ago. 2020. 